Original Article

\title{
Management of non-absorbable mesh infection after hernia repair by negative pressure wound therapy
}

\author{
Amreen Faruq, HM Sabbir Raihan, Muhtarima Haque \\ Department of Surgery, BIRDEM General Hospital and Ibrahim Medical College
}

\begin{abstract}
Background and objectives: Mesh infection following hernia repair has previously often resulted in removal of mesh. The aim of this study was to evaluate if negative pressure wound therapy (NPWT) can be used to treat such complications and preserve the mesh.

Materials and method: A prospective study was carried in the Department of Surgery, BIRDEM General Hospital from January 2017 to January 2019. Patients with deep wound infection and exposed infected mesh after hernioplasty were included in the study. Patients' demographics, existing comorbidities and outcome were recorded. All patients were treated with NPWT till the wound was covered with healthy granulation tissue and closed.

Results: NPWT was used to treat 7 patients with mesh infection following hernia repair. There was 2 male and 5 female cases and age ranged from 38-58 years. With NPWT the mesh in 6 patients (86\%) out of 7 could be completely salvaged and wound closed with secondary suturing. However, in 1 patient although the mesh covered with granulation tissue by NPWT and wound was closed; but it had to be partly removed later on due to development of chronic discharging sinus 20 days after stitch removal.
\end{abstract}

Conclusion: The study demonstrated that NPWT was a useful technique for the treatment and preservation of infected mesh after hernia repair.

IMC J Med Sci 2019; 13(1): 008. EPub date: 20 June 2019

\section{Introduction}

The use of prosthetic mesh in the repair of abdominal wall hernias that occur either due to open or laparoscopic surgery is the gold standard treatment. Mesh repair significantly reduces hernia recurrence by $30 \%$ [1-3]. However, as with any prosthetic implant the mesh is susceptible to infection. The reported incidence of mesh infection following hernia repair varies from $1 \%$ to as high as 7-8\% [4-8]. The rate of mesh infection following hernia repair in our hospital is not available. The exact incidence may be difficult to find probably due to its variable presentation with symptoms starting in early postoperative period to several years after surgery. Mesh infection is a misery for the patient as it is associated with longer hospital stay, added expenditure and emotional trauma. The recommended treatment for mesh infection involving non absorbable mesh is early surgical removal of the mesh and wound care [4-10]. However, this may leave behind a more complex open wound with an abdominal wall weakness, resulting in a recurrent hernia.

Negative pressure wound therapy (NPWT) is a newer technique used in the management of wound infection. This therapy enhances wound healing by (a) removing excess exudates, (b) providing a controlled moist environment, and (c) promoting neovascularization and granulation tissue formation. Moreover, it also stimulates shrinking of the wound size [11-13]. Taking into account of these properties, the present study was undertaken to evaluate the NPWT in the salvation/management of infected mesh of hernioplasty cases.

\footnotetext{
Address for Correspondence:

Dr. Amreen Faruq, Assistant Professor, Department of Surgery, BIRDEM General Hospital, 122 Kazi Nazrul Islam Avenue, Shahbag, Dhaka 1000.E-mail: dramreen78@yahoo.com
} 


\section{Materials and Methods}

This prospective study was carried out in the department of Surgery, BIRDEM General Hospital from January 2017 to January 2019. Patients included in the study were informed of the treatment options and informed written consent was obtained.

Study population: All patients diagnosed with deep wound and mesh infection/exposure following hernia repair (incisional, inguinal, umbilical, paraumbilical) were included in the study. Minor superficial surgical site infection following mesh repair were excluded.

Mesh infection was defined as presence of local signs of wound infection namely purulent discharge /pus or abscess formation at the level of mesh with positive microbiological culture results. Superficial surgical site infection was defined as infection that occurred within 30 days of surgery involving skin and subcutaneous tissue of incision while deep surgical site infection was defined as infection involving deep soft tissue (fascia, muscle) [14].

Information regarding age, body mass index (BMI)), presence of comorbidities , site of hernia wound and size, type of mesh used for the repair of hernia and number of days when infection occurred after hernioplasty operation were recorded in a pre-designed data sheet.

Negative pressure wound therapy (NPWT): After obtaining consent, negative pressure wound therapy (NPWT) was employed for the management/ salvation of the infected mesh.

NPWT procedure involved controlled application of sub-atmospheric pressure to a local environment using a sealed wound dressing connected to a vacuum pump [15]. Initially the wound size was measured and surgical debridement of the wound
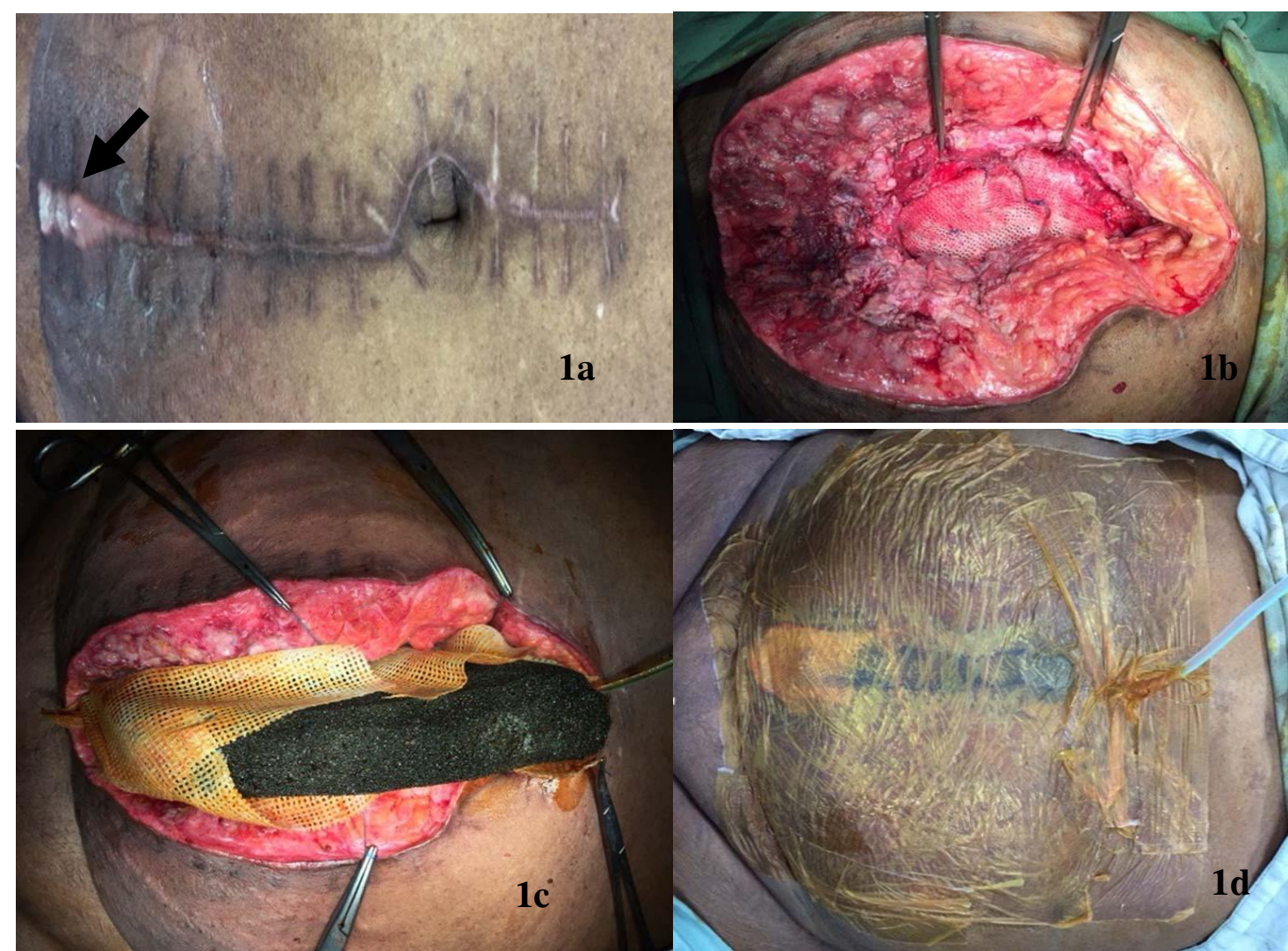

Fig-1a. Wound infection after hernioplasty (mesh repair) in an incisional hernia (arrow); 1b: Wound showing exposed mesh after debridement; 1c: NPWT dressing-Black sponge wrapped in Sofratulle being placed in wound; 1d: Airtight occlusive dressing on abdominal wound. 
was done under general or spinal anesthesia. Then, wound size was again measured after debridement and NPWT applied. A sterile black sponge was cut into specific size according to shape, size and depth of the prepared wound. A tube with multiple perforations at one end was placed within the sponge ensuring that the end with perforations remained inside the sponge and the rest taken out through the sponge. The sponge was soaked in $10 \%$ povidone iodine solution and wrapped with Sofratulle (medicated Vaseline gauge) to prevent adherence of the sponge to the wound. The sponge was then placed on the wound just above the mesh; ensuring that the mesh was in firm contact with the underlying wound surface. A transparent occlusive and adhesive dressing was applied over the sponge and the tube brought out through it making sure that the dressing was airtight (Fig 1a, b, c, d). The drainage tube was connected to commercially available portable suction machine or wall mounted suction devices.
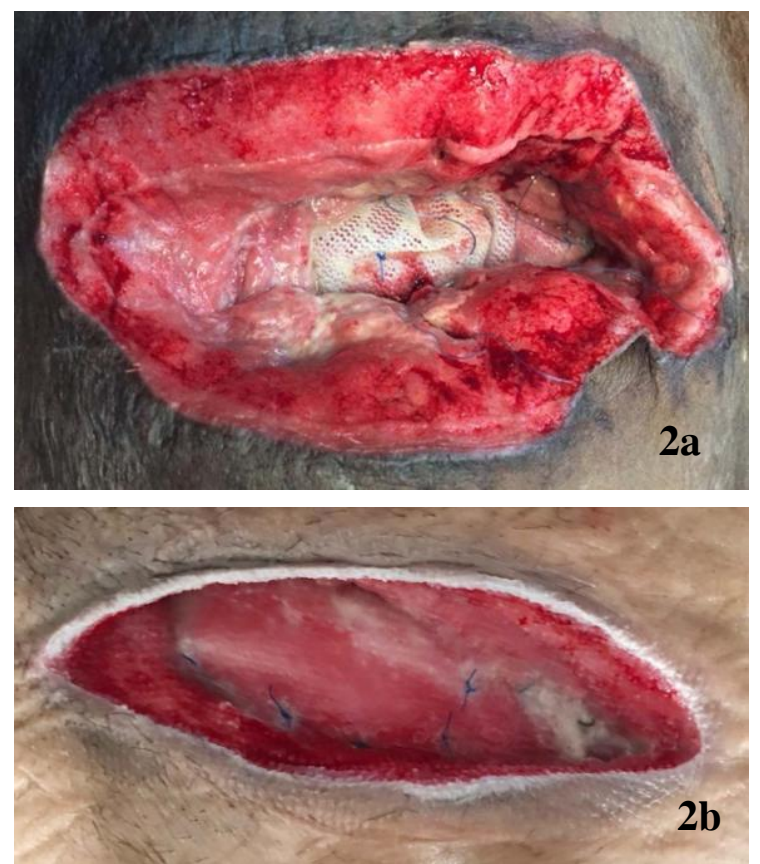

Fig-2a. Granulation tissue formation after two sessions of NPWT; 2b: Wound and exposed mesh covered with granulation tissue.

The negative pressure was set to-100 to- $120 \mathrm{~mm}$ $\mathrm{Hg}$ during the entire NPWT treatment. Suction was automated at 10 minutes interval. Initially the
NPWT dressing was opened every third day and a new dressing given, this was done for first 2 sessions then dressing changed every $5^{\text {th }}$ day or once a week depending on the wound condition. The dressing was continued till the wound and mesh was covered with healthy granulation tissue (Fig $2 \mathrm{a}$ and $2 \mathrm{~b}$ ). The wound was irrigated with normal saline mixed with $10 \%$ povidone iodine (3:1) once daily through the tube. Systemic antibiotics were used according to the results of culture and sensitivity.

The NPWT was continued till the mesh was covered with granulation tissue. Once the wound was covered with healthy granulation it was cleaned with normal saline and wound closure planned. The wounds were closed either by suture or skin graft depending on the size of the wounds. Healing by secondary intention was allowed in cases where suture or skin graft was not possible. After wound closure, the patients were carefully followed up till wound healed and stitches were removed. Duration of NPWT and length of total hospital stay were also recorded. Sample of wound swab was taken from each case for culture and sensitivity test.

There was a follow up plan for 3 years for each patient from the time of wound closure to observe any delayed wound infection, fistula or hernia recurrence.

\section{Results}

A total of 7 patients were included in this study. Out of 7 cases, 4 were patients primarily operated at BIRDEM General Hospital and 3 were referred from different hospitals after developing wound infection following hernioplasty operation. Among the study patients, $71 \%(5 / 7)$ were female and $29 \%$ $(2 / 7)$ were male. The mean age and BMI of the study patient were $47.85 \pm 6.84$ years and $30.02 \pm$ $4.97 \mathrm{~kg} / \mathrm{m}^{2}$ respectively. About $57 \%$ of study patients presented with incisional hernia. Incisional hernia was present mostly in older patients $(>50$ years) and paraumbilical hernia was present in relatively younger patients ( $<45$ years).

Polypropylene mesh was used in majority of the patients $(5 / 7,71 \%$; Table- 1$)$. The mean postoperative day of diagnosis of wound infection was 7.71 \pm 2.56 days (range 4-11 days). Male patients 
developed infection earlier $(<6$ post operative day) than female patients.

Table-1: Types of hernia and mesh used in study population

\begin{tabular}{lll}
\hline Parameters & Number & \% \\
\hline Incisional hernia & 4 & 57.1 \\
Paraumbilical hernia & 2 & 28.6 \\
Inguinal hernia & 1 & 14.3 \\
Polypropylene mesh & 5 & 71.4 \\
Polyester mesh & 2 & 28.6 \\
\hline
\end{tabular}

Table-2 describes the co-morbidities of the study patients. All the patients were diabetic. Hypertension, chronic kidney disease, bronchial asthma and hypothyroidism were present in $57.1 \%, 42.9 \%, 29 \%$ and $14 \%$ of the study patients respectively. Out 7 cases, 6 had multiple or more than one comorbidity.

Table-3 shows the pattern of bacteria isolated from the 7 cases prior to instituting NPWT. Pseudomonas sp was present in $42 \%$ patients either individually or in combination with other bacteria such as Esch. coli or Klebsiella sp. Out of 7 cases, 4 had wound infection with single bacteria while 3 had multiple organisms.

Table-4 shows the size of the wound of the individual case before and after completion of NWPT. Wound size was measured after first debridement and after 3 sessions of NPWT in all patients and finally before closure. There was 22$24 \%$ reduction in wound size after completion of NPWT in all 7 patients.
Table-3: Pattern of organisms isolated from wound samples of study cases $(n=7)$

\begin{tabular}{cl}
$\begin{array}{c}\text { Case } \\
\text { No. }\end{array}$ & \multicolumn{1}{c}{ Organisms isolated } \\
\hline 1 & Staphylococcus aureus \\
2 & Methicillin resistant Staphylococcus \\
& aureus (MRSA) \\
3 & Proteus $\mathrm{sp}+$ Klebsiella $\mathrm{sp}$ \\
4 & Esch. coli + Pseudomonus $\mathrm{sp}$ \\
5 & Streptococcus $\mathrm{sp}$ \\
6 & Pseudomonus $\mathrm{sp}$ \\
7 & Pseudomonus $\mathrm{sp}+$ Klebsiella $\mathrm{sp}$ \\
\hline
\end{tabular}

Out of the 7 patients with mesh infection, the mesh could be left in situ and infection controlled in 6 (86\%) patients (Table-5). In 1(14\%) patient after application of NPWT the mesh did cover with granulation tissue and secondary closure was done; but after 20 days of wound healing the patient developed a chronic discharging sinus. The wound was re-explored and the mesh partially removed and subsequently wound closure was done.

The average duration of received NPWT therapy was $37 \pm 12.5$ days. The average length of hospital stay was $48.5 \pm 11.2$ days (range 38 to 67 days; Table- 4). Length of hospital stay was the period of occurrence of infection/mesh exposure to the achievement of wound closure and release of patient from the hospital.

The first patient completed 2 years of follow up. No recurrence of hernia occurred in any patient after 6 to 24 months of follow up.

Table-2: Details of co-morbidities present in all patients

\begin{tabular}{cccccc}
\hline $\begin{array}{c}\text { Case } \\
\text { No. }\end{array}$ & $\begin{array}{c}\text { Diabetes } \\
\text { mellitus }\end{array}$ & Hypertension & $\begin{array}{c}\text { Chronic kidney } \\
\text { disease }\end{array}$ & $\begin{array}{c}\text { Bronchial } \\
\text { asthma }\end{array}$ & Hypothyroidism \\
\hline 1 & $\sqrt{ }$ & $\sqrt{ }$ & $\mathrm{x}$ & $\mathrm{x}$ & $\mathrm{x}$ \\
2 & $\sqrt{ }$ & $\mathrm{x}$ & $\mathrm{x}$ & $\mathrm{x}$ & $\mathrm{x}$ \\
3 & $\sqrt{ }$ & $\mathrm{x}$ & $\mathrm{x}$ & $\mathrm{x}$ & $\sqrt{ }$ \\
4 & $\sqrt{ }$ & $\sqrt{ }$ & $\sqrt{ }$ & $\sqrt{ }$ & $\mathrm{x}$ \\
5 & $\sqrt{ }$ & $\sqrt{ }$ & $\mathrm{x}$ & $\mathrm{x}$ & $\mathrm{x}$ \\
6 & $\sqrt{ }$ & $\mathrm{x}$ & $\sqrt{ }$ & $\sqrt{ }$ & $\mathrm{x}$ \\
7 & $\sqrt{ }$ & $\sqrt{ }$ & $3(42.9 \%)$ & $2(28.6 \%)$ & $1(14.3 \%)$ \\
\hline
\end{tabular}

Note: $\sqrt{=}$ Disease present; $x=$ Disease absent 
Table-4: Wound size before and after completion of NPWT

\begin{tabular}{ccc}
\hline $\begin{array}{c}\text { Case } \\
\text { No }\end{array}$ & $\begin{array}{c}\text { Wound size after } \\
\text { debridement }(\mathbf{c m})\end{array}$ & $\begin{array}{c}\text { Wound size at the } \\
\text { end of NPWT }(\mathbf{c m})\end{array}$ \\
\hline 1 & $20 \times 11$ & $15.5 \times 8.8$ \\
2 & $17 \times 6$ & $13 \times 5$ \\
3 & $14 \times 9$ & $11 \times 7.1$ \\
4 & $17 \times 8$ & $14 \times 6$ \\
5 & $9 \times 5$ & $8 \times 4$ \\
6 & $14 \times 10$ & $11 \times 8$ \\
7 & $15 \times 10$ & $11.5 \times 8$ \\
\hline
\end{tabular}

Table-5: Outcome of NPWT

\begin{tabular}{ll}
\hline Outcome of NPWT & Values \\
\hline Outcome of NPWT & \\
Number of mesh salvaged (\%) & $6(86 \%)$ \\
Number of mesh removed (\%) & $1(14 \%)$ \\
Mean ( \pm SD) duration of & $37 \pm 12.5$ \\
NPWT (days) & (Range 21-56) \\
Mean ( \pm SD) length of hospital & $48.5 \pm 11.2$ \\
stay during NPWT (days) & (Range 38-67) \\
\hline
\end{tabular}

\section{Discussion}

Mesh infection after hernia repair is a dreadful complication. With regard to patient outcome, it is a surgical failure with a psychological trauma and financial burden to patient. Conventionally, the infected mesh is removed and the purpose of using prosthesis to strengthen the hernia defect is lost. When wound dehiscence exposes the abdominal mesh, biofilm forming bacteria colonize the implant. Aggregates of microorganisms embedded in biofilms become highly resistant to antibiotics [15]. Therefore, early removal of the infected mesh is the treatment of choice in order to remove the source. NPWT by virtue of its mechanical effect removes exudates; so if the exudates and the biofilm can be removed by the negative pressure effect then it will be possible to keep the mesh in situ. Wolvos in a retrospective study demonstrated reduction in bacterial load and exudates with a decrease in inflammatory markers with vacuum assisted closure instillation [16]. In addition, NPWT stimulates the formation of granulation tissue, promotes angiogenesis and cellular proliferation [11-13,17]; thus, expedites wound healing. With attribute to such qualities we decided to utilize NPWT in management of mesh infection following hernia repair and aimed at mesh preservation. By now, NPWT is an established modality of treatment of acute, chronic and non healing wounds. It has also proved its utility in patients with compromised healing [18]. Comorbidities such as diabetes, obesity, renal disease, steroid therapy, nutritional deficiency have been associated with increased chances of infection and slow wound healing [7,19-22]. The reasons identified for delayed wound healing are reduced perfusion of skin and subcutaneous tissue and immune suppression [23]. NPWT appeared a promising option for our patients as they had multiple associated comorbidities with mesh infection. Biologic mesh has been advocated as a useful option in high risk patients due to its ability to resist infection [24]. These are expensive and not readily available. In our study polypropylene mesh had been used in five patients and polyester mesh in two patients and we tried to preserve them. Although, Stremitzer et al in their study suggested conservative management for absorbable or biologic mesh grafts but recommended removal of infected non absorbable mesh [9]. We have tried to preserve non absorbable mesh and have been successful in six out of seven cases. Lehner et al in a prospective study reported $86.4 \%$ implant retention in thirty two patients with infected orthopaedic prostheses using VAC-instillation (NPWT) combined with systemic antibiotics [25]. Berrevot et al reported a similar study like ours where they used conventional VAC (NPWT) therapy and were able to salvage mesh in 60 patients of 63 and commented infected large pore meshes could be salvaged by topical negative pressure therapy [26]. However, we did not take pore size into consideration. It is important to mention that NPWT simplifies the management of such wound infection. It is comfortable to the patient though with some amount of restriction in movement but avoids heavy dressing or repeated change of dressing which is often required in such infections. Patients of infected mesh treated with conventional management and mesh removal have a long hospital stay. Length of hospital stay of our patients was apparently shorter, though we did not 
have any comparative control cases. In our present study, all patients remained in hospital till stitch removal. However, a retrospective study by Garcia-Ruano et al on 45 patients showed no statistical difference in hospital stay between the two groups [27]. In future cases, we plan to discharge our patients after first session of NPWT that is within 3-4 days of diagnosis of wound infection. We also planned to use available portable inexpensive VAC machines so that patients could be discharged early, monitored as outpatient then readmitted for wound closure. The patients will be taught how to maintain the portable device at home. This would significantly reduce both hospital stay and cost. Most important, NPWT can be used to avoid mesh removal thus reducing chance of hernia recurrence.

The study had some limitations. This study had small sample size and lacked control group. A larger control trial is necessary to prove the usefulness of NPWT as an effective method for salvation of the infected mesh used in hernioplasty.

Mesh infection after hernia repair usually necessitates a return trip to the operating theatre and removal of the infected mesh with a possibility of recurrence of hernia. NPWT may be cost effective compared to conventional method in terms of daily dressing expense, number of surgical procedures required and length of hospital stay till full recovery.

\section{Authors' contributions}

AF designed the study, collected data and wrote the manuscript; HMSR and MH involved in patient follow up.

\section{Conflict of Interest}

The authors declare no conflict of interest.

\section{Funding: None}

\section{References}

1. MacFadyen BV, Mathis CR. Inguinal herniorrhaphy: complications and recurrence. Semin Laparoscopic Surg. 1994; 1: 128.
2. Dabbas N, Adams K, Pearson K, Royle GT. Frequency of abdominal wall hernias: is classical teaching out of date? J R Soc Med Short Rep. 2011; 2(1): 5.

3. Hesselink VJ, Luijendijk RW, de Wilt JH, Jeekel J. An evaluation of risk factors in incisional hernia recurrence. Surg Gynaecol Obstet. 1993; 176: 228-234.

4. Szczerba SR, Dumanian GA, Definitive surgical treatment of infected or exposed ventral hernia mesh. Ann Surg. 2003; 237(3): 437-41.

5. Delikoukos S, Tzovaras G, Liakou P. Late onset deep mesh infection after inguinal hernia repair. Hernia. 2007; 11(1): 15-17.

6. Cobb WS, Harris JB, LokeyJS et al. Incisional herniorraphy with intraperitoneal composite mesh; a report of 95 cases. Am Surg. 2003; 69(9): 784-87.

7. Petersen S, Henke G, Freitag M et al. Deep prosthesis infection in incisional hernia repair: predictive factors and clinical outcome. Eur $J$ Surg. 2001; 167(6): 453-457.

8. Falagas ME, Kasiakou SK. Mesh related infection after hernia repair. Clin Microbiol Infect. 2005; 11(1): 3-8.

9. Stremitzer S, Bachleitner-Hofmann T, Gradl B, Gruenbeck M, Bachleitner-Hofmann B. Mesh graft infection following abdominal hernia repair: risk factor evaluation and strategies of mesh graft preservation. A retrospective analysis of 476 operations. World J Surg. 2010; 34(7): 1702-1709.

10. Aufenacker TJ, Koelemay M, Gouma DJ, Simons MP. Systematic review and metaanalysis of the effectiveness of antibiotic prophylaxis in prevention of wound infection after mesh repair of abdominal wall hernia. $\mathrm{Br}$ J Surg. 2006; 93(1): 5-10.

11. Argenta LC, Morykwas MJ. Vaccum assisted closure: a new method for wound control and treatment: clinical experience. Ann Plast Surg. 1997; 38(6): 563-76.

12. Moues CM, van den Bemd GJ, Heule F. Comparing conventional gauze therapy to vcaccum-assisted closure wound therapy: A 
prospective randomised trial. $J$ Plast Reconstr Aesthet Surg. 2007; 60(6): 672-81.

13. Morykwas MJ, Simpson J, Punger K. Vacuum assisted closure: state of basic research and physiologic foundation. Plast Reconstr Surg. 2004; 91(1): 105-11.

14. Falagas ME, Kasiakou SK. Mesh related infections after hernia repair surgery. Clin Microbiol Infect. 2006; 11: 3-8.

15. Cipolla J, Baillie DR, Steinberg SM, Martin ND, JaiK NP. Negative pressure wound therapy: Unusual and innovative application. OPUS 12 Scientist. 2008; 2(3): 15-29.

16. Wolvos T. Wound instillation- the next step in negative pressure wound therapy. Lessons learned from initial experiences. Ostomy Wound Manage. 2004; 50(11): 56-66.

17. Greenberg JJ. Can infected composite mesh be salvaged? Hernia.2010; 14: 589-592.

18. Raad W, Lantis II JC, Tyrie L, Gendis C, Todd G. Vacuum assisted closure instill as a method of sterilizing venous stasis wounds prior to split thickness skin graft placement. Int Wound J. 2010; 7: 81-85.

19. Jezupovs A, Mihelsons M. The analysis of infection after polypropylene mesh repair of abdominal wall hernia. World J Surg. 2006; 30: $2270-2278$.

20. Delikoukos S, Tzovaras G, Liakou, Mantzos F, Hatzitheofilou C. Late onset deep mesh infection after inguinal hernia repair. Hernia. 2007; 11: 15-17.
21. Malone DL, Genuit T, Tracy JK. Surgical site infections: reanalysis of risk factors. J Surg Res. 2002; 103: 89-95.

22. Arroyo A, Garcia P, Perez F. Randomized clinical trial comparing suture and mesh repair of umbilical hernia repair in adults. Br J Surg. 2001; 88: 1321-1323.

23. Aguilar B, Alyssa B, Chapital MD. Conservative management of mesh site infection in hernia repair. $J$ Laparoendose $A d v$ Surg Tech. 2010; 20(3): 249-252.

24. Adrales G. Biological meshes-indications and shortcomings. Challenging hernias postgraduate course. 12 $2^{\text {th }}$ World Congress of Endoscopic Surgery, Maryland, USA. 2010.

25. Lehner B, Fleischmann W, Becker R, Jukema GN. First experiences with negative pressure wound therapy and instillation in the treatment of infected orthopaedic implants: a clinical observational study. Int Orthop. 2011; 35: 1415-1420.

26. Berrevoet F, Vanlander A, Sainz-Barriga M, Rogiers $\mathrm{X}$, Troisi $\mathrm{R}$. Infected large pore meshes may salvaged by topical negative pressure therapy. Hernia. 2013; 17: 67-73.

27. Garcia-Ruano A, Deleyto E, Garcia-Fernandez S. VAC-instillation therapy in abdominal mesh exposure: a novel indication. $J$ Surg Res. 2016; 206: 292-297. 